\title{
Influence of dimethyl dicarbonate on the resistance of Escherichia coli to a combined UV-Heat treatment in apple juice
}

\author{
Maria Gouma', Elisa Gayán ${ }^{1,2}$, Javier Raso', Santiago Condón' and Ignacio Álvarez ${ }^{1 *}$ \\ ${ }^{1}$ Departamento de Producción Animal y Ciencia de los Alimentos, Tecnología de los Alimentos, Facultad de Veterinaria, \\ Universidad de Zaragoza, Zaragoza, Spain, ${ }^{2}$ Laboratory of Food Microbiology, Department of Microbial and Molecular \\ Systems, Katholieke Universiteit Leuven, Leuven, Belgium
}

OPEN ACCESS

Edited by:

Henry Jaeger.

University of Natural Resources and Life Sciences, Vienna, Austria

Reviewed by:

Juan Aguirre,

Prince Edward Island University,

Canada

Maria Gougouli,

Aristotle University of Thessaloniki,

Greece

*Correspondence:

Ignacio Álvarez,

Departamento de Producción Animal

y Ciencia de los Alimentos,

Tecnología de los Alimentos, Facultad de Veterinaria, Universidad

de Zaragoza, Miguel Servet 177,

50013 Zaragoza, Spain

nacho.alvarez@unizar.es

Specialty section:

This article was submitted to

Food Microbiology,

a section of the journa

Frontiers in Microbiology

Received: 16 March 2015 Accepted: 06 May 2015

Published: 19 May 2015

Citation:

Gouma M, Gayán E, Raso J,

Condón S and Álvarez I (2015)

Influence of dimethyl dicarbonate on the resistance of Escherichia coli to a combined UV-Heat treatment in apple

Front. Microbiol. 6:501. doi: 10.3389/fmicb.2015.00501
Commercial apple juice inoculated with Escherichia coli was treated with UV-C, heat $\left(55^{\circ} \mathrm{C}\right)$ and dimethyl dicarbonate - DMDC $(25,50$, and $75 \mathrm{mg} / \mathrm{L})-$, applied separately and in combination, in order to investigate the possibility of synergistic lethal effects. The inactivation levels resulting from each treatment applied individually for a maximum treatment time of 3.58 min were limited, reaching 1.2, 2.9, and $0.06 \log _{10}$ reductions for UV, heat, and DMDC $(75 \mathrm{mg} / \mathrm{L})$, respectively. However, all the investigated combinations resulted in a synergistic lethal effect, reducing the total treatment time and UV dose, with the synergistic lethal effect being higher when larger concentrations of DMDC were added to the apple juice. The addition of $75 \mathrm{mg} / \mathrm{L}$ of DMDC prior to the combined UV-C light treatment at $55^{\circ} \mathrm{C}$ resulted in $5 \log _{10}$ reductions after only 1.8 min, reducing the treatment time and UV dose of the combined UV-Heat treatment by $44 \%$.

Keywords: Escherichia coli, UV-C light, heat, apple juice, dimethyl dicarbonate

\section{Introduction}

Apple juice is one of the most popular juices in developed countries due to its pleasant organoleptic properties, ranking third in the EU fruit juice and nectars market (AIJN, 2012). Several foodborne disease outbreaks associated with the consumption of apple juice have implicated Escherichia coli O157:H7 as a potential pathogen (Besser et al., 1993; Cody et al., 1999; Vojdani et al., 2008). In response, the (United States Food and Drug Administration [USFDA], 2001) considered this microorganism a pertinent pathogen for juices, requiring that juice processors apply a treatment that results in at least $5-\log _{10}$ reductions of its population in fruit and vegetable juices.

Thermal pasteurization has been predominantly used in the juice industry to avoid this danger. However, its adverse effects on the nutritional and sensorial quality properties of the end product-as well as consumers' demands for minimally processed, freshlike products-have impelled food research to develop non-thermal food processing technologies. Among them, UV-C radiation has shown a considerable potential effect for juice pasteurization. In fact, the (National Advisory Committee on Microbiological Criteria for Foods of the United States Department of Agriculture [NACMCF], 2006) revised the definition of "pasteurization" in 2004 and included UV irradiation as an alternative to 
heat that can be used for pasteurization purposes. UV-C radiation is considered a promising alternative to traditional heat treatments due to its various advantages such as the effectiveness in the inactivation of a wide range of both pathogen and spoilage microorganisms, the absence of toxic residues, the simple operation and maintenance and the low energy consumption (Guerrero-Beltrán and Barbosa-Cánovas, 2004). Nevertheless, its high dependence on the optical properties of the treated liquid (e.g., turbidity, absorption coefficient) renders it insufficient to achieve the required $5-\log _{10}$ reductions imposed by the USFDA under industrially applicable treatment conditions (Murakami et al., 2006; Koutchma, 2008). To overcome this disadvantage, research has focused on the development of combined processes based on the hurdle technology approach, aiming to increase the lethal effect of UV-C radiation. To this direction, combinations with other non-thermal technologies and mild heat treatments as well as its combination with antimicrobial agents have been investigated (Koivunen and Heinonen-Tanski, 2005; Wu et al., 2011). For instance, UV$\mathrm{C}$ treatments in combination with pulsed electric fields (PEFs; Gachovska et al., 2008) and high-intensity ultrasounds (US; Char et al., 2010) have resulted in an additive lethal effect. On the contrary, the combination of UV-C radiation and mild heat (UV$\mathrm{H})$ has demonstrated a synergistic inactivation of $E$. coli in fruit juices (Gayán et al., 2012a,b). In particular, a combined UV-H treatment $\left(3.9 \mathrm{~J} / \mathrm{mL}\right.$ at $55^{\circ} \mathrm{C}$ for $3.6 \mathrm{~min}$ ) has been designed, with which it has been possible to inactivate $5-\log _{10}$ cycles of a cocktail of pathogenic E. coli strains in apple juice without impairing the quality attributes of the product (Gayán et al., 2012a). However, this treatment could be too long to be applied on an industrial scale. Therefore, new combined treatments that enable reducing the intensity of these treatments could be of interest.

Dimethyl dicarbonate is a powerful microbial inhibitor by inactivating cellular enzymes (Bartowsky, 2009). It is primarily used to prevent yeast spoilage in wine, where it is added before bottling, and undergoes complete hydrolysis within a few hours to methanol and carbon dioxide, which are both natural constituents of the product. Its effectiveness against yeasts in alcoholic beverages has been well proven and evaluated (Daudt and Ough, 1980; Costa et al., 2008). However, its lethal effectiveness varies among species and strains (Bartowsky, 2009). Studies on grape must have demonstrated that bacteria were more resistant than yeast to DMDC (Delfini et al., 2002). DMDC can also be used as a microbial control agent in non-carbonated $100 \%$ juice beverages up to a maximum concentration of $250 \mathrm{ppm}$ (United States Food and Drug Administration [USFDA], 2000). In this case, beverages must be produced under good manufacturing conditions and their microbial load must first be reduced by current technologies such as heat treatment or filtration prior to the addition of DMDC (United States Food and Drug Administration [USFDA], 2013). To our knowledge, there is a dearth of published data on the use of DMDC in the inactivation of pathogenic bacteria in fruit juices and, in particular, on its combined application with mild heat treatments and UV-H light. Thus, the objective of this study was to investigate the inactivation effect of UV-C light, mild heat and DMDC alone and in combination against E. coli in clarified apple juice.

\section{Materials and Methods}

\section{Bacterial Culture}

Escherichia coli strain STCC 4201, provided by the Spanish Type Culture Collection (STCC), was used. The bacterial culture was frozen at $-80^{\circ} \mathrm{C}$ in cryovials. Stationary-phase cultures were prepared by inoculating $5 \mathrm{~mL}$ of tryptone soy broth (Oxoid, Hampshire, UK) supplemented with $0.6 \%$ (w/v) yeast extract (Oxoid; TSBYE) with a colony grown on tryptone soy agar (Oxoid) supplemented with $0.6 \%(\mathrm{w} / \mathrm{v})$ yeast extract (TSAYE). The precultures were incubated at $35^{\circ} \mathrm{C}$ for $6 \mathrm{~h}$ in a shaking incubator. Fifty microliters of the precultures were inoculated into $50 \mathrm{~mL}$ of fresh TSBYE and incubated for $24 \mathrm{~h}$ under the same conditions, which resulted in stationary-phase cultures containing approximately $2 \times 10^{9} \mathrm{CFU} / \mathrm{mL}$.

\section{Treatment Medium}

Commercial clarified apple juice (Pascual S.L., Córdoba, Spain) was purchased from a local market. It presented a $\mathrm{pH}$ of 3.6 , an absorption coefficient of $24.9 \mathrm{~cm}^{-1}$ and a turbidity of 2.4 NTU. Turbidity was measured using an HI 83749 nephelometer (Hanna Instrument, Szeged, Hungary). The $\mathrm{pH}$ measurements $\left(20 \pm 1^{\circ} \mathrm{C}\right)$ were performed with a $\mathrm{pH}$ meter (Basic $20 \mathrm{pH}$ meter; Crison Instrument, Barcelona, Spain) with a glass electrode (Crison) and calibrated before measurement at $\mathrm{pH}$ 4.0, 7.0, and 9.0. Absorbance of apple juice was measured at $254 \mathrm{~nm}$ using a Libra S12 spectrophotometer (Biochrom Ltd., Cambridge, UK). Sample solutions were diluted and evaluated using quartz cuvettes (Hellma, Móllheim, Germany) with path lengths of 1, 2 , and $10 \mathrm{~mm}$. The absorption coefficient of the sample solution was determined by the slope of the absorbance versus path length, correcting the dilution factor.

When DMDC was used, a stock solution of DMDC ( $\geq 99 \%$; Merck, Darmstad, Germany) was purchased, and after being divided into smaller volumes it was stored at $-80^{\circ} \mathrm{C}$. The solution was brought to room temperature before its use. To evaluate the lethality of DMDC, different concentrations (from 0 to $250 \mathrm{ppm}$ ) of the compound were added to $10 \mathrm{~mL}$ of apple juice previously inoculated with $10^{6} \mathrm{CFU} / \mathrm{mL}$ of $E$. coli population. At preset treatment times, $0.1 \mathrm{~mL}$ samples were taken, immediately diluted in $0.1 \%$ peptone water (Oxoid) and then poured into plates using TSAYE.

\section{UV-C, Heat, and UV-H Treatments}

All the treatments performed in the study were carried out with the equipment previously described by Gayán et al. (2011). The system consisted of eight individual annular thin-film flowthrough reactors connected sequentially. Each reactor consisted of a low-pressure UV lamp fixed at the axis of an outer glass tube and enclosed by a quartz tube. In the annular gap $(2 \mathrm{~mm})$ a stainless steel coil spring was introduced in order to improve the flow's turbulence. To conduct UV-H treatments, the entire unit 
was submerged in a $90-\mathrm{L}$ water tank heated by the circulating water of a peripheral thermostatic bath. A heating/cooling coil exchanger was placed before the inlet of the first reactor and submerged in the water bath to ensure that the treatment medium reached the desired temperature before entering the reactor. Heat treatments were performed using the same equipment with the lamps switched off.

The apple juice was inoculated with the bacterial suspension to achieve approximately $10^{6} \mathrm{CFU} / \mathrm{mL}$. After the addition of the DMDC solution $(0,25,50$, or $75 \mathrm{mg} / \mathrm{L})$, the juice was thoroughly mixed and immediately pumped through the equipment at a flow rate of $8.5 \mathrm{~L} / \mathrm{h}$. When the flow rate stabilized, samples were withdrawn through the sampling valves at the outlet of each reactor. Then, appropriate dilutions of samples were done and immediately pour-plated.

\section{Incubation of Treated Samples and Survival Counting}

Tryptone soy agar with yeast extract (TSAYE; Oxoid) was used as the recovery medium, and plates were incubated for $24 \mathrm{~h}$ at $35^{\circ} \mathrm{C}$. Previous experiments demonstrated that longer incubation times did not change the number of survivors. After incubation, colony forming units (CFU) were counted with an improved image analyzer automatic colony counter (Protos, Synoptics, Cambridge, UK), as described by Condón et al. (1996). A detection limit of $30 \mathrm{CFU} /$ plate was set. Each experiment was performed at least three times on separate days. Average results are presented in tables and figures.

\section{Results and Discussion}

It has been demonstrated that the application of UV-C light at moderate temperatures has resulted in a synergistic microbial lethal effect when liquid food products are treated (Geveke, 2008; Gayán et al., 2012a,b). More specifically, in the case of juices, a temperature of $55^{\circ} \mathrm{C}$ and a treatment time of $3.6 \mathrm{~min}$ and a UV dose of $3.9 \mathrm{~J} / \mathrm{mL}$ have been indicated as the optimum conditions to exploit the synergistic effect resulting from the combined UV-H treatment, reducing five or more $\log _{10}$ cycles of different pathogenic microorganisms, including $E$. coli and Listeria monocytogenes (Gayán et al., 2012a,b, 2015). In spite of these promising results, the required processing times to achieve the $5-\log _{10}$ reductions demanded by the FDA for the pasteurization of fruit juices should be too long for the industrial application of the technology. Therefore, the purpose of this investigation was to study the occurrence of the synergistic effect of the proposed UV-H process when antimicrobials like DMDC are added to the juice. The existence of this synergism could reduce the treatment time or the UV dose to reach the required $5-\log _{10}$ reductions, in this case, of E. coli. Thus, apple juice inoculated with E. coli STCC 4201 was treated with UV-C light, mild heat $\left(55^{\circ} \mathrm{C}\right)$ and different concentrations of DMDC (25, 50 , and $75 \mathrm{mg} / \mathrm{L}$ ), applied separately and in combination. E. coli STCC 4201 was chosen because it has been proved to be the most UV resistant among different E. coli strains (Gayán et al., 2011).
In a first approach and in order to evaluate the lethality of DMDC, E. coli inactivation over time due to its exposition to different concentrations of this compound added to clarified apple juice was investigated at $25^{\circ} \mathrm{C}$ (Figure 1). As observed, microbial inactivation increased with time and concentration, enabling a reduction of up to $3-\log _{10}$ cycles after $30 \mathrm{~min}$ and 250 ppm, which is the maximum concentration that the FDA permits in non-carbonated $100 \%$ juice beverages (United States Food and Drug Administration [USFDA], 2000). Published data on the inactivation of $E$. coli by DMDC in liquid food vary strongly. $1.66 \log _{10}$ cycles reduction of E. coli ATCC 8739 in litchi juice was achieved as exposed to $150 \mathrm{mg} / \mathrm{L} \mathrm{DMDC} \mathrm{at}$ $30^{\circ} \mathrm{C}$ for $1 \mathrm{~h}$, and the inactivation rate during initial $1 \mathrm{~h}$ was far greater than during the remaining $5 \mathrm{~h}$ (Yu et al., 2014). Fisher and Golden (1998) observed that E. coli O157:H7 (initial concentration $10^{7} \mathrm{CFU} / \mathrm{mL}$ ) survived for up to 3, 9, and 2 days in apple cider containing $250 \mathrm{ppm}$ of DMDC at 4,10 , and $25^{\circ} \mathrm{C}$, respectively. A $5-\log _{10}$ reduction of $E$. coli $\mathrm{O} 157: \mathrm{H} 7$ in apple cider was achieved with $250 \mathrm{ppm}$ of DMDC with a holding time of $1.30 \mathrm{~h}$ at room temperature (Basaran-Akgul et al., 2009). In this investigation and in order to find out the synergistic lethal effects when combined with UV and heat, the maximum concentration of DMDC that did not affect the number of $E$. coli survivors during a maximum processing time of $10 \mathrm{~min}$ was used. Indeed, the longest processing time for the UV and heat process was of $3.6 \mathrm{~min}$. Therefore, concentrations of $75 \mathrm{ppm}$ did not interfere with $E$. coli inactivation, and thus, this concentration was added to apple juice for the following investigations.

Table 1 summarizes the inactivation of E. coli STCC 4201 achieved in apple juice after the application of the maximum UV$\mathrm{H}$ treatment $(3.9 \mathrm{~J} / \mathrm{mL}$ and $3.58 \mathrm{~min}$ ), which was possible to apply in our facility at a temperature of $55^{\circ} \mathrm{C}$. For comparisons, the lethality of the different individual treatments in presence or not

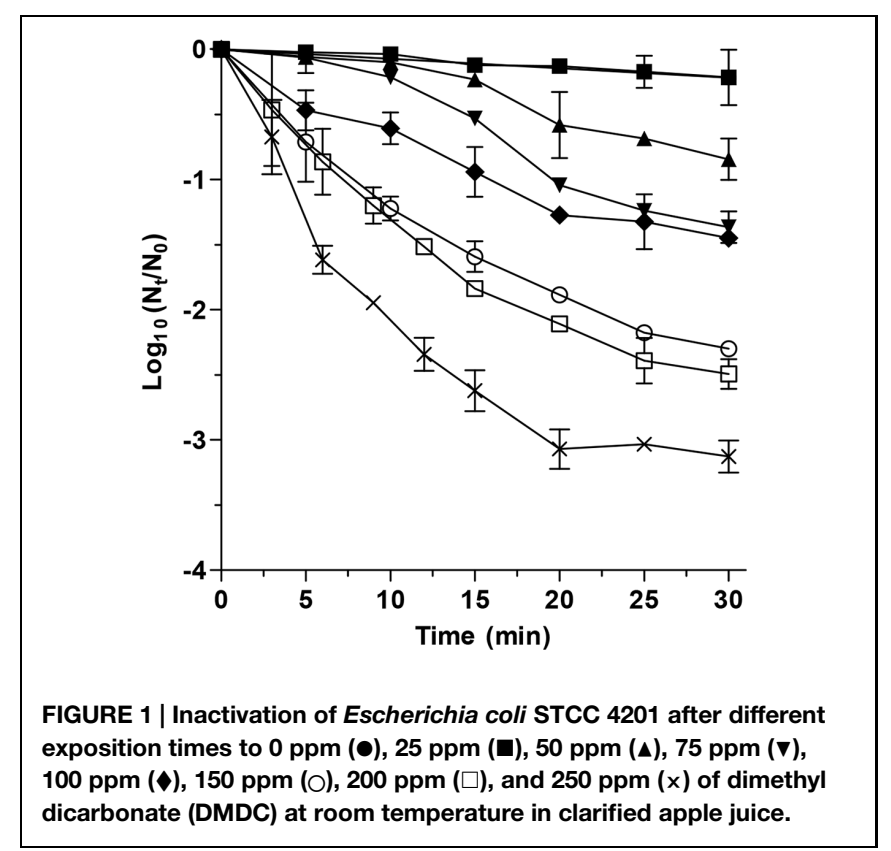


TABLE 1 | $\log _{10}$ cycles of inactivation of Escherichia coli STCC 4201 in apple juice after different heat, UV, and UV-H treatments in presence of different concentrations of dimethyl dicarbonate (DMDC).

\begin{tabular}{lll}
\hline Treatment & Log $_{\mathbf{1 0}}$ cycles of inactivation & Treatment time (min) \\
\hline UV & $1.2(0.1)$ & 3.58 \\
HEAT $\left(55^{\circ} \mathrm{C}\right)$ & $2.9(0.5)$ & 3.58 \\
DMDC $(75 \mathrm{mg} / \mathrm{L})$ & $0.06(0.01)$ & 3.58 \\
HEAT $+25 \mathrm{mg} / \mathrm{L}$ & $3.2(0.6)$ & 3.58 \\
HEAT $+50 \mathrm{mg} / \mathrm{L}$ & $3.8(0.2)$ & 3.58 \\
HEAT $+75 \mathrm{mg} / \mathrm{L}$ & $4.4(0.1)$ & 3.58 \\
UV + HEAT & $5.1(0.1)$ & 3.20 \\
UV + $25 \mathrm{mg} / \mathrm{L}$ & $1.63(0.02)$ & 3.58 \\
UV + 50 mg/L & $2.3(0.2)$ & 3.58 \\
UV + 75 mg/L & $2.9(0.1)$ & 3.58 \\
UV + HEAT + $25 \mathrm{mg} / \mathrm{L}$ & $>6.0$ & 3.58 \\
UV + HEAT + 50 mg/L & $>6.0$ & 2.67 \\
UV + HEAT + 75 mg/L & $>6.0$ & 2.23 \\
\hline
\end{tabular}

Numbers in parentheses indicate the standard deviations.

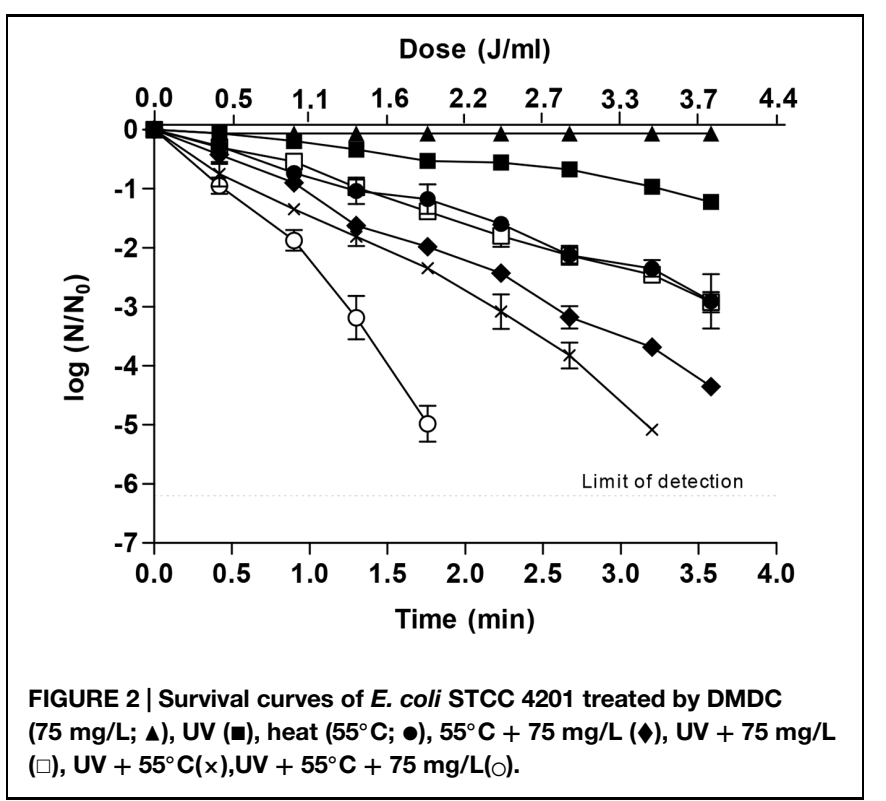

of distinct concentrations of DMDC has been included. When the achieved lethality was higher than that of the detection limit of the recovery technique, treatment time was reduced. As observed, the inactivation levels resulting from each treatment applied individually for the maximum applied treatment time were limited, with the heat treatment being the most effective, reaching approximately $3-\log _{10}$ cycles of inactivation. The addition of DMDC synergistically increased the lethality of both heat and UV radiation, mainly when the DMDC concentration was higher than $25 \mathrm{mg} / \mathrm{L}$. At this concentration, the lethal effect was additive: over $25 \mathrm{mg} / \mathrm{L}$, the higher the concentration the greater the synergistic lethal effect. Thus, the addition of $75 \mathrm{mg} / \mathrm{L}$ of DMDC (0.06 $\log _{10}$ reductions when DMDC was used alone) increased by $1.5 \log _{10}$ cycles the inactivation effect of heat $\left(2.9 \log _{10}\right.$ reductions when heat was used alone), diminishing the E. coli population by $4.4 \log _{10}$ cycles after $3.58 \mathrm{~min}$ of treatment. When
$50 \mathrm{mg} / \mathrm{L}$ of DMDC was added, the lethality increased by $0.9 \log _{10}$ cycles. A similar synergistic lethal effect was observed when 75 or $50 \mathrm{mg} / \mathrm{L}$ of DMDC were added before the UV treatment. The final inactivation levels reached with the combined processes were 2.9 and $2.3 \log _{10}$ reductions when 75 or $50 \mathrm{mg} / \mathrm{L}$ of DMDC were added, respectively, which corresponded to an increase of 1.7 and $1.1 \log _{10}$ cycles compared to the addition of the lethalities of the individual treatments, respectively. Similar results have been described in literature on the combined effect of DMDC with UV light. Thus, it has been demonstrated that the concurrent use of UV $\left(18.3 \mathrm{~mJ} / \mathrm{cm}^{2}\right)$ and DMDC (250 and $500 \mathrm{ppm}$ ) on the inactivation of L. monocytogenes in chilled brine was more effective than either of the treatments alone (Parikh et al., 2011). Halim et al. (2012) reported that the addition of DMDC $(15 \mu \mathrm{L} / 100 \mathrm{~mL})$ to red pitaya juice prior to $\mathrm{UV}$ treatment resulted in a twofold microbial reduction compared to individual treatments. Quicho (2005) reported that DMDC (75 and $150 \mathrm{ppm}$ ) was effective in reducing E. coli ATCC 25922 population in apple cider in conjunction with UV $(13.7 \mathrm{~mJ} / \mathrm{mL})$, producing more than $6 \log _{10}$ reductions when added prior to UV treatment, when the latter alone produced a inactivation of $4.7 \log _{10}$ cycles. The higher level of inactivation obtained in that investigation could be due to a less resistant strain of $E$. coli was used. Daudt and Ough (1980) reported that the amount of DMDC to sterilize wine inoculated with various strains of yeasts depended mainly on the yeast strain. Moreover, the applied UV dose was manually recorded using sensors that were located on the outermost wall of the interior of the flow chamber, which does not correspond to the UV dose received by the cells in the medium. In addition, no information was indicated concerning the optical properties of the apple cider such as the absorption coefficient and the turbidity, that play a key role in the inactivation efficacy of UV treatment (Koutchma, 2008). The presence of alcohol in apple cider can also result in an increased effectiveness of DMDC (Porter and Ough, 1982). On the other hand, various studies have focused on the effect of UV light on E. coli populations in apple juice (Wright et al., 2000; Basaran et al., 2004; Franz et al., 2009; Müller et al., 2011). Nevertheless, a comparison of the data obtained in this investigation with other published data is difficult to do based on UV dosage only due to substantial differences in the conformation and geometry of the UV equipment used in each case, flow pattern and optical properties of the treatment medium (turbidity and absorption coefficient), which play an important role in UV germicidal efficacy (Koutchma et al., 2004).

From Table 1, it can also be observed that the maximum lethal effect obtained in this investigation was achieved when the three hurdles were combined simultaneously. Thus, the treatment of a clarified apple juice with UV and mild heat $\left(55^{\circ} \mathrm{C}\right)$ ensured more than $6 \log _{10}$ cycles of inactivation in $3.58,2.67$, and $2.23 \mathrm{~min}$ of treatment time when 25,50 , or $75 \mathrm{mg} / \mathrm{L}$ of DMDC were added, respectively. These results indicate a synergistic lethal effect of at least $1.8 \log _{10}$ reductions when only $25 \mathrm{mg} / \mathrm{L}$ of DMDC was used after applying the UV-H combined process. With higher concentrations of DMDC, the synergistic lethal effect would be higher since the treatment time to achieve more than $6 \log _{10}$ reductions 
(maximum plate count detection limit in this investigation) was reduced.

In order to optimize the treatment conditions (UV dose and treatment time) required to achieve $5-\log _{10}$ reductions of the investigated microorganism in apple juice by the combined process at $55^{\circ} \mathrm{C}$ in the presence of $75 \mathrm{mg} / \mathrm{L}$ of DMDC, survival curves where obtained (Figure 2). As observed, microbial inactivation increased with the treatment time for heat, UV or the different combined processes, as well as with the dose for the UV-based treatments. When UV was applied, survival curves showed an initial lag phase followed by an exponential inactivation rate, as has been described in the literature (Sastry et al., 2000; Koutchma et al., 2009; Gouma et al., 2015). However, the length of this shoulder was reduced when UV light was combined with heat, and the decrease was more noticeable when DMDC was added to the apple juice. Shoulder length has been related to damage repair capacity (Quintero-Ramos et al., 2004; López-Malo and Palou, 2005; Gayán et al., 2011, 2012c). Therefore, shorter shoulders could be due to a reduction in cellular capacity to repair damage or to the appearance of additional lethal damage that arises from the interaction of lesions induced by the applied hurdles. Since DMDC has been described as a powerful microbial inhibitor by inactivating cellular enzymes, and in this investigation the lethality of $75 \mathrm{mg} / \mathrm{L}$ DMDC was demonstrated when prolonging treatment exposition times over $10 \mathrm{~min}$ (Figure 1), this compound could impair cellular lesions with shorter exposition times, improving the effectiveness of UV-C light, heat or the combined process UV-H and diminishing the length of the shoulders or even causing them to disappear.

Independently of the kinetics of inactivation, Figure 2 shows that the microbial inactivation of the individual treatments reached, in the best case, $3 \log _{10}$ cycles. This lethality was increased when combining hurdles achieving near $5 \log _{10}$ reductions when heat was applied in the presence of $75 \mathrm{mg} / \mathrm{L}$ of DMDC after 3.6 min or $5 \log _{10}$ reductions when UV-C light $(3.4 \mathrm{~J} / \mathrm{mL})$ was applied at $55^{\circ} \mathrm{C}$ over $3.2 \mathrm{~min}$. However, the simultaneous application of UV-C light and heat $\left(55^{\circ} \mathrm{C}\right)$ in the presence of $75 \mathrm{mg} / \mathrm{L}$ of DMDC reduced the treatment time and

\section{References}

AIJN, E. F. J. A. (2012). Liquid Fruit: Market Report [Online]. Available at: http://www.aijn.org/pages/main/file.handler?f=AIJNMarketReport2012.pdf (accessed September 03, 2015).

Bartowsky, E. J. (2009). Bacterial spoilage of wine and approaches to minimize it. Lett. Appl. Microbiol. 48, 149-156. doi: 10.1111/j.1472-765X.2008. 02505.x

Basaran, N., Quintero-Ramos, A., Moake, M. M., Churey, J. J., and Worobo, R. W. (2004). Influence of apple cultivars on inactivation of different strains of a Escherichia coli O157:H7 in apple cider by UV irradiation. Appl. Environ. Microbiol. 70, 6061-6065. doi: 10.1128/aem.70.10.6061-6065.2004

Basaran-Akgul, N., Churey, J. J., Basaran, P., and Worobo, R. W. (2009). Inactivation of different strains of Escherichia coli O157:H7 in various apple ciders treated with dimethyl dicarbonate (DMDC) and sulfur dioxide (SO2) as an alternative method. Food Microbiol. 26, 8-15. doi: 10.1016/j.fm.2008. 07.011
UV dose by up to $1.8 \mathrm{~min}$ and $1.96 \mathrm{~J} / \mathrm{mL}$, respectively, for a $5-\log _{10}$ reduction of $E$. coli STCC 4201 in apple juice. That is, the addition of DMDC to the apple juice prior to the UV-Heat combined treatment reduced the processing time and the UV-C dose of the latter by $44 \%$. Although the presence of $75 \mathrm{mg} / \mathrm{mL}$ of DMDC noticeably reduced the UV-H processing conditions needed to achieve a $5-\log _{10}$ cycles reduction of the population of a UV-resistant microorganism like E. coli STCC 4201, more research is considered necessary to define processing conditions (treatment time, temperature, UV dose) more suitable for use on an industrial scale and to evaluate the lethal effectiveness of the combined process in other microorganisms. Moreover, DMDC has been proved to be an antimicrobial compound with a great lethal effect on bacteria like $E$. coli when applied alone, and even more when it was combined with heat and/or UV$\mathrm{C}$ light. Therefore, its mechanism of inactivation in bacteria deserves further research when applied alone or in combined processes-like the one proposed in this investigation-in order to extend the application of such combined processes to other food products, enabling the inactivation of different kinds of microorganisms including yeast and Gram-positive and Gramnegative bacteria.

\section{Acknowlegments}

This study has been carried out with financial support from the Ministerio de Ciencia e Innovación de España, the project AGL 2012-33522 from Comisión Interministerial de Ciencia y Tecnología (CICYT), EU-FEDER (CIT020000-200940), and "Departamento de Ciencia, Tecnología y Universidad del Gobierno de Aragón.” EG gratefully acknowledges the financial support for her doctoral studies from the Ministerio de Educación y Ciencia de España. This work was also performed in the framework of the postgraduate program partly financed by the Act "Greek State Scholarships Foundation (I.K.Y.) grants program for the academic year 2012-2013, through an individualized academic assessment" funded by the Operational Program "Education and Lifelong Learning" of the European Social Fund (ESF) and the NSRF (2007-2013).

Besser, R. E., Lett, S. M., Weber, J. T., Doyle, M. P., Barrett, T. J., Wells, J. G., et al. (1993). An outbreak of diarrhea and hemolytic uremic syndrome from Escherichia coli O157:H7 in fresh-pressed apple cider. JAMA 269, 2217-2220. doi: 10.1001/jama.1993.035001700 47032

Char, C., Mitilinaki, E., Guerrero, S., and Alzamora, S. (2010). Use of highintensity ultrasound and UV-C light to lnactivate some microorganisms in fruit juices. Food Bioprocess Technol. 3, 797-803. doi: 10.1007/s11947-0090307-7

Cody, S. H., Glynn, M. K., Farrar, J. A., Cairns, K. L., Griffin, P. M., Kobayashi, J., et al. (1999). An outbreak of Escherichia coli O157:H7 infection from unpasteurized commercial apple juice. Ann. Intern. Med. 130, 202-209. doi: 10.7326/0003-4819-130-3-199902020-00005

Condón, S., Palop, A., Raso, J., and Sala, F. J. (1996). Influence of the incubation temperature after heat treatment upon the estimated heat resistance values of spores of Bacillus subtilis. Lett. Appl. Microbiol. 22, 149-152. doi: 10.1111/j.1472-765X.1996.tb01130.x. 
Costa, A., Barata, A., Malfeito-Ferreira, M., and Loureiro, V. (2008). Evaluation of the inhibitory effect of dimethyl dicarbonate (DMDC) against wine microorganisms. Food Microbiol. 25, 422-427. doi: 10.1016/j.fm.2007.10.003

Daudt, C. E., and Ough, C. S. (1980). Action of dimethyldicarbonate on various yeasts. Am. Soc. Enol. Vitic. 31, 21-23.

Delfini, C., Gaia, P., Schellino, R., Strano, M., Pagliara, A., and Ambro, S. (2002). Fermentability of grape must after inhibition with dimethyl dicarbonate (DMDC). J. Agric. Food Chem. 50, 5605-5611. doi: 10.1021/jf0256337

Fisher, T. L., and Golden, D. A. (1998). Survival of Escherichia coli O157:H7 in apple cider as affected by dimethyl dicarbonate, sodium bisulfite, and sodium benzoate. J. Food Sci. 63, 904-906. doi: 10.1111/j.1365-2621.1998.tb17923.x

Franz, C. M. A. P., Specht, I., Cho, G.-S., Graef, V., and Stahl, M. R. (2009). UV$\mathrm{C}$-inactivation of microorganisms in naturally cloudy apple juice using novel inactivation equipment based on Dean vortex technology. Food Control 20, 1103-1107. doi: 10.1016/j.foodcont.2009.02.010

Gachovska, T. K., Kumar, S., Thippareddi, H., Subbiah, J., and Williams, F. (2008). Ultraviolet and pulsed electric field treatments have additive effect on inactivation of E. coli in apple juice. J. Food Sci. 73, M412-M417. doi: 10.1111/j.1750-3841.2008.00956.x

Gayán, E., Monfort, S., Álvarez, I., and Condón, S. (2011). UV-C inactivation of Escherichia coli at different temperatures. Innov. Food Sci. Emerg. Technol. 12, 531-541. doi: 10.1016/j.ifset.2011.07.008

Gayán, E., Serrano, M., Monfort, S., Álvarez, I., and Condón, S. (2012a). Pasteurization of apple juice contaminated with Escherichia coli by a combined UV-mild temperature treatment. Food Bioprocess Technol. 6, 3006-3016. doi: 10.1007/s11947-012-0937-z

Gayán, E., Serrano, M. J., Monfort, S., Álvarez, I., and Condón, S. (2012b). Combining ultraviolet light and mild temperatures for the inactivation of Escherichia coli in orange juice. J. Food Eng. 113, 598-605. doi: 10.1016/j.jfoodeng.2012.07.018

Gayán, E., Serrano, M. J., Raso, J., Alvarez, I., and Condon, S. (2012c). Inactivation of Salmonella enterica by UV-C light alone and in combination with mild temperatures. Appl. Environ. Microbiol. 78, 8353-8361. doi: 10.1128/AEM.02010-12

Gayán, E., Serrano, M. J., Pagán, R., Álvarez, I., and Condón, S. (2015). Environmental and biological factors influencing the UV-C resistance of Listeria monocytogenes. Food Microbiol. 46, 246-253. doi: 10.1016/j.fm.2014.08.011

Geveke, D. J. (2008). UV inactivation of E-coli in liquid egg white. Food Bioprocess Technol. 1, 201-206. doi: 10.1007/s11947-008-0070-1

Gouma, M., Álvarez, I., Condón, S., and Gayán, E. (2015). Modelling microbial inactivation kinetics of combined UV-H treatments in apple juice. Innov. Food Sci. Emerg. Technol. 27, 111-120. doi: 10.1016/j.ifset.2014.11.004

Guerrero-Beltrán, J. A., and Barbosa-Cánovas, G. V. (2004). Advantages and limitations on processing foods by UV light. Food Sci. Technol. Int. 10, 137-147. doi: 10.1177/1082013204044359

Halim, H., Noranizan, M., Sobhi, B., Sew, C. C., Karim, R., and Osman, A. (2012). Nonthermal pasteurization of pitaya (Hylocereus polyrhizus) juice using the hurdle concept. Int. Food Res. J. 19, 1457-1461.

Koivunen, J., and Heinonen-Tanski, H. (2005). Inactivation of enteric microorganisms with chemical disinfectants, UV irradiation and combined chemical/UV treatments. Water Res. 39, 1519-1526. doi: 10.1016/j.watres.2005.01.021

Koutchma, T. (2008). UV light for processing foods. Ozone Sci. Eng. 30, 93-98. doi: $10.1080 / 01919510701816346$

Koutchma, T., Forney, L. J., and Moraru, C. I. (2009). Ultraviolet Light in Food Technology: Principles and Applications. Boca Raton, FL: CRC Press. doi: 10.1201/9781420059519

Koutchma, T., Keller, S., Chirtel, S., and Parisi, B. (2004). Ultraviolet disinfection of juice products in laminar and turbulent flow reactors. Innov. Food Sci. Emerg. Technol. 5, 179-189. doi: 10.1016/j.ifset.2004.01.004

López-Malo, A., and Palou, E. (2005). "Ultraviolet light and food preservation," in Novel Food Processing Technologies, eds G. V. Barbosa-Cánovas, M. S. Tapia, and M. P. Cano (Madrid: CRC Press), 464-484.
Müller, A., Stahl, M. R., Graef, V., Franz, C. M. A. P., and Huch, M. (2011). UV-C treatment of juices to inactivate microorganisms using Dean vortex technology. J. Food Eng. 107, 268-275. doi: 10.1016/j.jfoodeng.2011.05.026

Murakami, E. G., Jackson, L., Madsen, K., and Schickedanz, B. (2006). Factors affecting the Ultaviolet inactivation of Escherichia coli $\mathrm{K} 12$ in apple juice and a model system. J. Food Process Eng. 29, 53-71. doi: 10.1111/j.17454530.2006.00049.x

National Advisory Committee on Microbiological Criteria for Foods of the United States Department of Agriculture [NACMCF]. (2006). Requisite scientific parameters for establishing the equivalence of alternative methods of pasteurization. J. Food Prot. 69, 1190-1216.

Parikh, P. P., Williams, R. C., Mallikarjunan, P., Eifert, J. D., and Marcy, J. E. (2011). Concurrent use of Ultraviolet light and citric acid, dimethyl dicarbonate and hydrogen peroxide to inactivate Listeria monocytogenes in chill brine. J. Food Saf. 31, 530-537. doi: 10.1111/j.1745-4565.2011.00331.x

Porter, L. J., and Ough, C. S. (1982). The effects of ethanol, temperature, and dimethyl dicarbonate on viability of Saccharomyces cerevisiae Montrachet No. 522 in wine. Am. J. Enol. Vitic. 33, 222-225.

Quicho, J. M. (2005). Efficacy of Ultraviolet Light in Combination with Chemical Preservatives for the Reduction of Escherichia coli in Apple Cider. Master thesis, Virginia Polytechnic Institute and State University, Blacksburg, VA.

Quintero-Ramos, A., Churey, J. J., Hartman, P., Barnard, J., and Worobo, R. W. (2004). Modeling of Escherichia coli inactivation by UV irradiation at different pH values in apple cider. J. Food Prot. 67, 1153-1156.

Sastry, S. K., Datta, A. K., and Worobo, R. W. (2000). Ultraviolet light. J. Food Sci. 65, 90-92. doi: 10.1111/j.1750-3841.2000.tb00623.x

United States Food and Drug Administration [USFDA]. (2000). Inventory of Effective Food Contact Substance (FCS). Notifications. FCN No. 35. Available at: http://www.accessdata.fda.gov/scripts/fdcc/?set=fcn\&id=35 (accessed January $31,2015)$.

United States Food and Drug Administration [USFDA]. (2001). Hazard Analysis and Critical Control Point (HACCP); Procedures for the Safe and Sanitary Processing and Importing of Juice; Final Rule (Washington, DC: Food and Drug Administration), 6138-6202.

United States Food and Drug Administration [USFDA]. (2013). Code of Federal Regulation, Title 21 - Food and drugs, Part 172 - Food additives permitted for direct addition to food for human consumption, Subpart B-Food preservatives, Sec. 172.133 Dimethyl dicarbonate (Washington, DC: USFDA Administration).

Vojdani, J. D., Beuchat, L. R., and Tauxe, R. V. (2008). Juice-associated outbreaks of human illness in the United States, 1995 through 2005. J. Food Prot. 71, 356-364.

Wright, J. R., Sumner, S. S., Hackney, C. R., Pierson, M. D., and Zoecklein, B. W. (2000). Efficacy of Ultraviolet Light for reducing Escherichia coli O157:H7 in unpasteurized apple cider. J. Food Prot. 63, 563-567.

Wu, D., You, H., Zhang, R., Chen, C., and Lee, D.-J. (2011). Ballast waters treatment using UV/Ag-TiO2 + O3 advanced oxidation process with Escherichia coli and Vibrio alginolyticus as indicator microorganisms. Chem. Eng. J. 174, 714-718. doi: 10.1016/j.cej.2011.09.087

Yu, Y., Xu, Y., Wu, J., Xiao, G., Wen, J., Chen, Y., et al. (2014). Inactivation of Escherichia coli and Staphyloccocus aureus in litchi juice by dimethyl dicarbonate (DMDC) combined with nisin. J. Food Res. 3, 1-9. doi: 10.5539/jfr.v3n3p1

Conflict of Interest Statement: The authors declare that the research was conducted in the absence of any commercial or financial relationships that could be construed as a potential conflict of interest.

Copyright ( 2015 Gouma, Gayán, Raso, Condón and Álvarez. This is an open-access article distributed under the terms of the Creative Commons Attribution License (CC BY). The use, distribution or reproduction in other forums is permitted, provided the original author(s) or licensor are credited and that the original publication in this journal is cited, in accordance with accepted academic practice. No use, distribution or reproduction is permitted which does not comply with these terms. 